\title{
An investigation into the neuromuscular control at the level of the upper limbs of junior handball girls players
}

\author{
Iconomescu Teodora-Mihaela $^{1 \mathrm{a}}$, Mindrescu Veronica ${ }^{2}$, and Talaghir Laurentiu-Gabriel ${ }^{1}$ \\ ${ }^{1}$ University Dunarea de Jos", Faculty of Physical Education and Sports, Street Garii, no. 63-64, \\ 800008, Galati, Romania \\ ${ }^{2}$ University Transilvania, Faculty of Physical Education and Sports Montana, Street Universităţii, no. \\ 1, 500068, Brașov, Romania
}

\begin{abstract}
In this paper we want to present the development of upper limb muscle control in sportswomen handball. Thus at the beginning and end of championship players girls were tested with one MOVE 1 DU device type, then centralized data obtained and analyzed statistically. Handball players' were 10 girls subjected search with the average age of 12.5 years, the average height of $165.5 \mathrm{~cm}$. and an average weight of $57.7 \mathrm{~kg}$. By centralizing data obtained we have seen an increase in upper limb neuromuscular control in final testing of statistically $\mathrm{p}<.05$. Statistical analysis confirms the hypothesis that the means to improve neuromuscular control if applied properly and psychomotor functional somatic features specific age increases the competitive performance.
\end{abstract}

Keywords: Neuromuscular control; player handball; development skill; performance.

\section{Introduction}

The learning process and the success of fine motricity behavioural activities in sports are the outcomes of the positive influence of the favourable heritable material and of the development of psychomotor skills and harmoniously combining mental functions with the metrical ones. Elaborated execution of a movement (skill) involves conjugation of the mental and emotional processes, under the guidance of conscience and of one self.

Success in sports performance depends on how efficiently the individual perceives and uses relevant sensory information. Knowing exactly where limbs are in space and how it is needed to perform a great muscular effort, to perform a certain action is essential for successful performance in all activities requiring complex coordination of different body

${ }^{a}$ Corresponding author: ticonomescu@ugal.ro

(C) The Authors, published by EDP Sciences. This is an open access article distributed under the terms of the Creative Commons Attribution License 4.0 (http://creativecommons.org/licenses/by/4.0/). 
parts. Fortunately, information about the position and movement of various body parts is available from peripheral receptors located around articular structures.

Motor abilities depend on how effectively the individual perceives and uses relevant sensory information. Exact knowledge of the layout of the limbs is critical and the muscular effort as it is also critical to perform a certain action (motor ability, motor skills, and motor action). Information about the position and movement of various parts of the body is perceived by different proprioceptive receptors, [3,4].

Proprioception, kinesthesia along with the efferent response occurring as a result of proprioreceptive impulse generates neuromuscular control, [1].

Riemann\&Lephart [8], define neuromuscular control 'as the unconscious activation of dynamic restraints occurring in preparation for and in response to joint motion and loading for the purpose of maintaining and restoring functional joint stability'. (p. 71)

The morphological characteristics of athletes play an important role in team sports. Handball is a complex game that requires players to adopt and develop aerobic and anaerobic capacities and several motor skills such as sprinting, jumping, flexibility and acceleration. These are considered important parameters of the game and they contribute to high performance of the player and of the team, [6,2 and 9].

Taking into account the fact that psycho motricity involves conjugation of the mental functions and the motor functions and that they develop best during junior age, we consider it appropriate and useful to study neuromuscular control of the upper limbs in athletes engaged in official competitions.

As a consequence, one can improve neuromuscular control (at the level of the upper limbs) of junior handball players. This control is utterly necessary and it gets involved in performing specific handball motor actions.

\section{Material and methods}

\subsection{Material and methods}

\subsubsection{Subjects}

The study was conducted on a group of 10 handball girls players' in the ACS Veraflor Brasov handball Sports Club. The players were tested at the beginning and at the end of the handball championship. The sports girls had an average age of 12.5 years, the average height of $165.5 \mathrm{~cm}$. and an average weight of $57.7 \mathrm{~kg}$.

\subsubsection{Materials}

The study of the neuromuscular control has been performed with 'Portable device for training neuromuscular control MOVE1 DU type' which is aimed for research and evaluation activities, training, human performance improvement and recovery.

\subsubsection{Methods}

To assess the score of the tested athletes we have used fundamental statistical parameters the average and standard deviation. To find significant differences between tests we have used student test pairs and the statistical significance was assessed at a level of $1 \%$ and $5 \%$ with statistical program by SPSS 20. 


\section{Procedure}

The subject, having a model - a graphical profile - displayed on the monitor screen, must execute movement traction, so as to determine the movement of a spot to watch the profile. The subject player views on the monitor screen the effects, throughout the movement, and based on information received, he/she has the possibility to continuously control and adjust the movement to achieve as closely the given model. In carrying out this process neuromuscular control speed has been carefully monitored both at high speed (brake 10\%) and low speed (brake 80\%), each sample having a total of 20 repetitions.

Description of the exercise: the upper limbs sitting on chair with stretched upward; grabbed the baton ends; thrust forward and down by flexing the forearm on the arm and elbow descent.

Each sport girl received a score after the initial and final testing and final scores for each of the two actions.
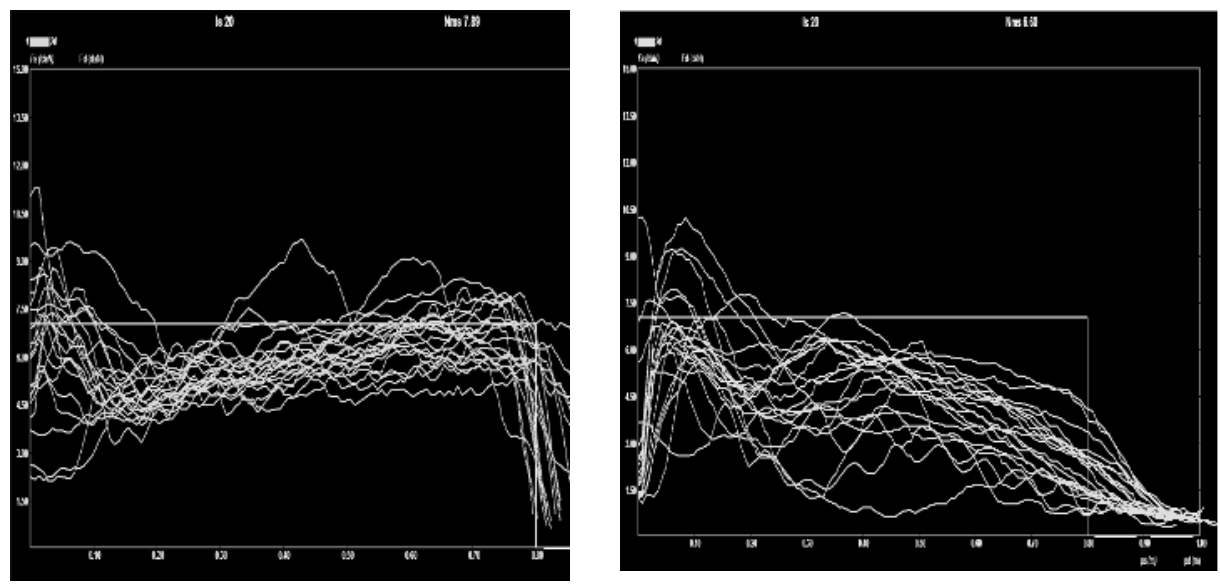

Fig.1. (a) Execution speed 80\%, score per exercise - 7.89; (b)Execution speed 10\%, score per exercise - 6.60

Thus after the initial testing we have seen that the sports girl succeeds in reaching the model imposed by the exercises with small execution speed, but fails to control the start and end of execution. In the case of high execution speed exercises, she fails to impart the strength to the speed required to achieve the task in the final phase of execution.

\subsection{Hypotheses}

The capacity of upper limb neuromuscular control in junior handball girls' players might be improved during the championship by specific training in order to participate in the competition (Romanian National Handball Championship). If the means to improve neuromuscular control are adequate to the functional somatic and psychomotor peculiarities specific of the age, competitive performance value increases.

\section{Results and discussions}

In conducting the research we have kept monitored if during the course of championship the athletes change their score on neuromuscular control of the lower limbs. 
The parameters studied were notes issued by software, notes deviations calculated according to the shape of the curves selected. They have values between 0 and 10 . At the end of each cycle predetermined arithmetic notes was issued. These were reflected in the parameters that we used to create the chart interpretation of results.

Thus after the initial and final testing we have centralized the obtained data and we have presented the data in the following tables (Table 1,2).

Table 1. Average of the points obtained at the initial and final testing of neuromuscular control at low speed.

\begin{tabular}{cccc}
\hline Testing & $\mathrm{M}$ & $\mathrm{N}$ & $\mathrm{SD}$ \\
\hline TI & 7.62 & 10 & .60 \\
TF & 8.04 & 10 & .53 \\
\hline
\end{tabular}

$\mathrm{M}$ - average, SD - standard deviation, $\mathrm{N}$ - number of subjects

Table 2. Statistical analysis between initial and final testing of neuromuscular control at low speed $(\mathrm{K}=80 \%)$.

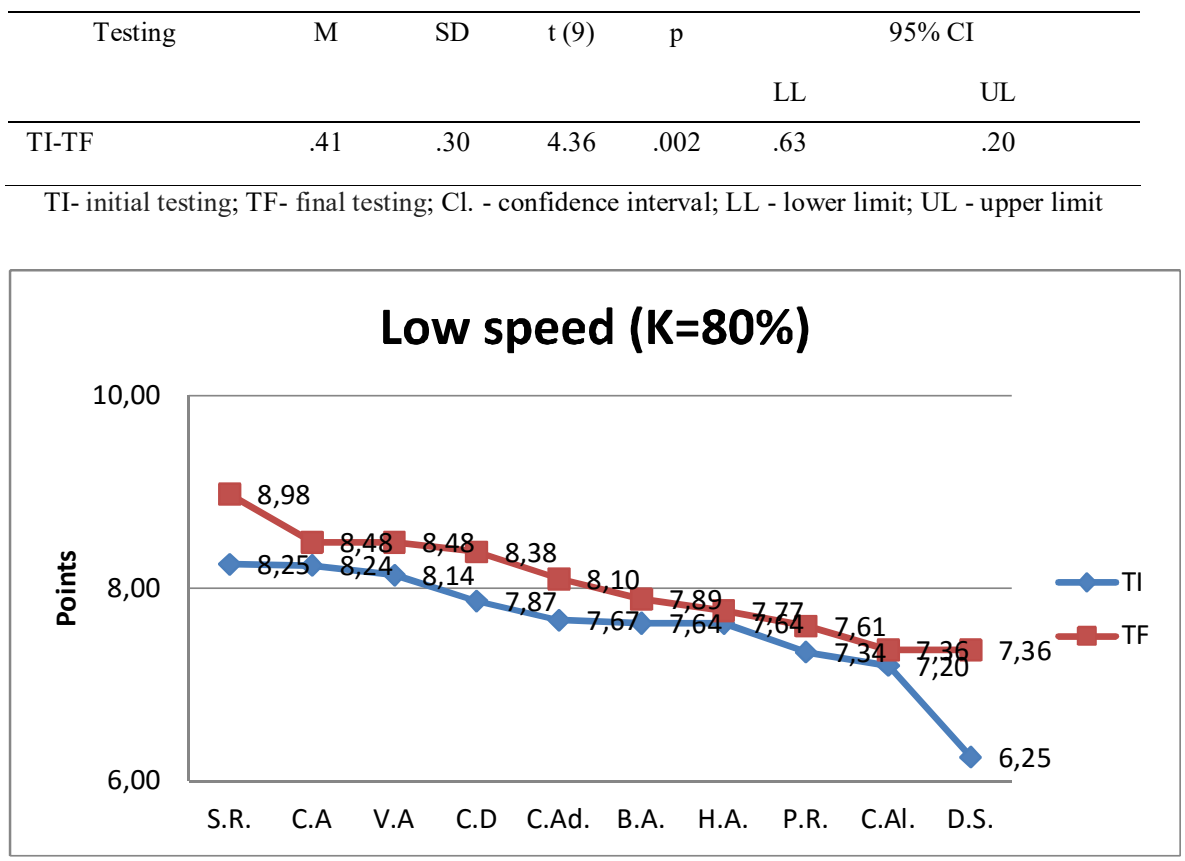

Fig. 2. Evolution of points according to the ranking at the level of the execution group at low execution $(\mathrm{K}=$ $80 \%)$.

The sports girl with the best neuromuscular control at the low speed execution level was, after initial testing, S.R. She got an overall score of 8.25 while the group average was 7.62. D.S. had the lowest neuromuscular control at low speed with an overall score of executions of 6.25 (Figure 2).

The sports girl with the best neuromuscular control at low execution speed in the final testing is the same S.R. She got an overall score of 8.98 in terms of executions while the group average was 8.04. D.S. and C.Al. have the lowest neuromuscular control at low speed with an overall score of executions of 7.36 (Figure 2). 
At the group level for testing neuromuscular control at low speed $(\mathrm{K}=80 \%)$ between initial and final tests there can be seen a significant progress of all athletes subjected to statistical analysis research highlighting a significance level of $\mathrm{p}<.05$ (Table 2).

Table 3. Average of the points obtained at the initial and final testing of neuromuscular control at high speed $(\mathrm{K}=$ $10 \%)$.

\begin{tabular}{llll}
\hline Testing & M & N & SD \\
\hline TI & 6.21 & 10 & .48 \\
TF & 6.71 & 10 & .38 \\
\hline \multicolumn{4}{l}{ M - average, SD - standard deviation, N- number of subjects }
\end{tabular}

Table 4. Statistical analysis between initial and final testing of neuromuscular control at low speed $(\mathrm{K}=10 \%)$.

\begin{tabular}{ccccccc}
\hline Testing & $\mathrm{M}$ & $\mathrm{SD}$ & $\mathrm{t}(9)$ & $\mathrm{p}$ & \multicolumn{2}{c}{$95 \% \mathrm{CI}$} \\
& & & & & $\mathrm{LL}$ & $\mathrm{UL}$ \\
\hline TI-TF & .50 & .46 & 3.42 & .008 & .83 & .17
\end{tabular}

TI- initial testing; TF- final testing; Cl. - confidence interval; LL - lower limit; UL - upper limit

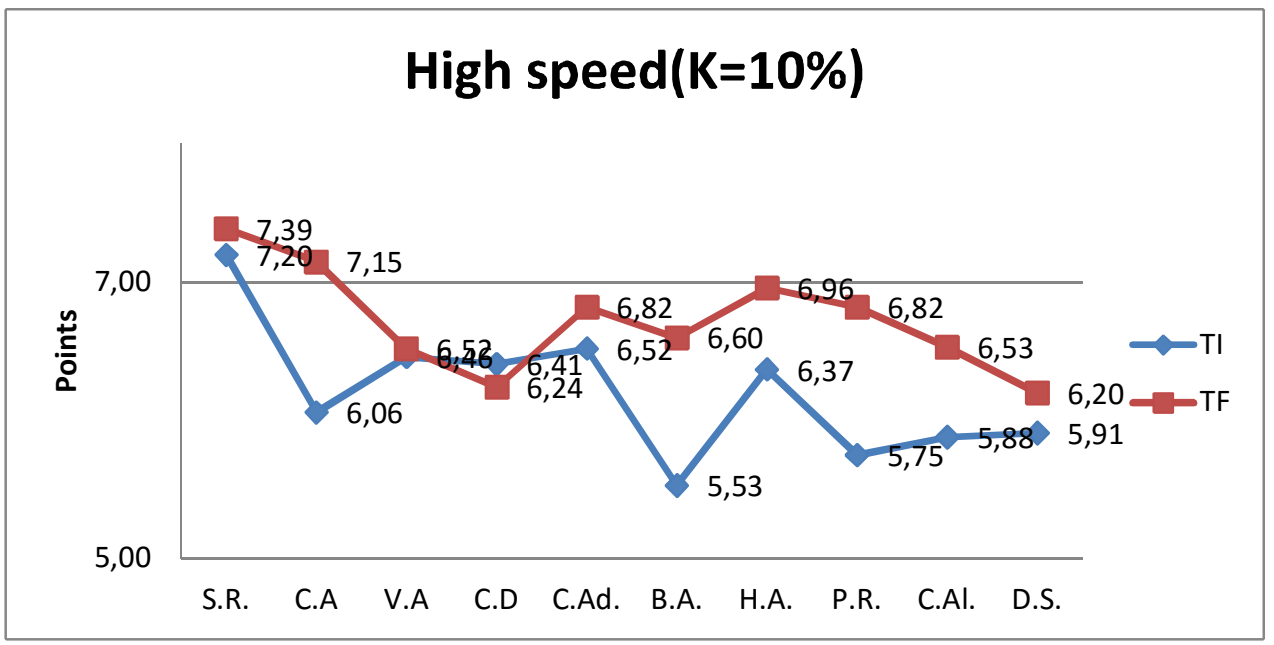

Fig. 3. Evolution of points according to the ranking at the level of the execution group at low execution $(\mathrm{K}=$ $10 \%)$.

The sports girl with the best neuromuscular control at the high speed execution level was, after initial testing, S.R. (Figure 3). She got an overall score of 7.20 while the group average was 6.21. BA had the lowest neuromuscular control at high speed with an overall score of executions of 5.53. S.D remains in the pole position whilst being the best within the group both at low and high speed execution.

The sports girl with the best neuromuscular control at high execution speed in the final testing is the same S.R. She got an overall score of 7.39 in terms of executions while the group average was 6.71. D.S. has the lowest neuromuscular control at high speed with an overall score of executions of 6.20 .

S.R. and C.A. are visibly better at neuromuscular control at high speed as compared to low speed. The remaining sports girls rank better at the level of execution speed within the small group, or about the same position in both cases. 
At the group level for testing neuromuscular control at low speed $(\mathrm{K}=80 \%)$ between initial and final tests there can be seen a significant progress of all athletes subjected to statistical analysis research highlighting a significance level of $\mathrm{p}<.05$ (Table 4).

\section{Conclusions}

Neuromuscular testing in the case of junior sports girls involved in official handball competitions gave us information on the organization and planning of their training in this period. Thus from the obtained information we could observe that the neuromuscular control of upper limb has improved up to the final testing no specific training being required.

Handball specific motor skills involve large neuromuscular control both high at speed and low speed. This sport which is based on both aerobic and anaerobic effort involves athletes both physically and mentally. This effort is intense because the age is small (12) and at a functional level the major systems involved in the effort have not been fully completed.

\section{References}

1. Cioroiul, S., Health Therapy, Concepts and Methods. Bloomington: Author House UK Ltd, (2014).

2. Enoka, R., Neuromechanics of Human Movement (ed. 3 rd). Boulder: Human Kinetics, (2002).

3. Girard O., Micallef J.P.\& Millet G.P., Lower-limb activity during the power serve in tennis: effects of performance level. Med Sci Sports Exerc, 37: 1021-29, (2005).

4. Yotani K., Tamaki H., Yuki A. et al., Response training shortens visuo-motor related time in athletes. Int J Sports Med, 32: 586-90, (2011).

5. Mosoi, A., \& Gugu Gramatopol, C., Neuromuscular control and lateralization in the game of tennis. Education Fancing Contemporary World Issue, 553-558, (2012).

6. Oxyzogloun, H.D., Oxyzoglou, N., Hatzimanouil, D., Iconomou, C., Ioannidis, T., Lazaridis, S., \& Papadopoulus, K., Evaluation off high-level handbal players in morphological characteristics and varios motor abilities by playing position. European Journal of Sports Medicine, 1(2), 21-28, (2014).

7. Puiu, M., Training Methodology to Increase Strength Parameter Based on Improved Neuromuscular Control Case Study. Sport Science Review, XXIII(1-2), 23-38. doi:0.2478/ssr-204-0002, (2014).

8. Riemann, B., \& Lephart, S., The Sensoriomotor System, Part I: The Physiologic Basis of Functional Joint Stability. Journal of Athletic Training, 37(1), 71-79, (2002).

9. Swartz, E., \& Bruce, L., Balance Training for Neuromuscular Control and Performance Enhancement: A Call for More Research. Athletic Trainig and Sports Health Care, 3(4), 71-173. doi:10.3928/19425864-20110629-05, (2011). 